Pineda, Claudia G.; Nakkula, Michael J.

\title{
Dancing ethnicity: A qualitative exploration of immigrant youth agency in an
} ethnically specific program

International journal for research on extended education : IJREE 2 (2014) 2, S. 79-103

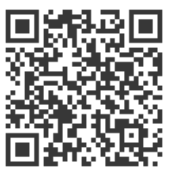

Quellenangabe/ Reference:

Pineda, Claudia G.; Nakkula, Michael J.: Dancing ethnicity: A qualitative exploration of immigrant youth agency in an ethnically specific program - In: International journal for research on extended education : IJREE 2 (2014) 2, S. 79-103 - URN: urn:nbn:de:0111-pedocs-229878 - DOI: 10.25656/01:22987

https://nbn-resolving.org/urn:nbn:de:0111-pedocs-229878

https://doi.org/10.25656/01:22987

in Kooperation mit / in cooperation with:

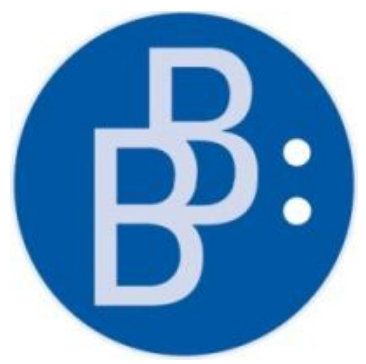

https://www.budrich.de

\section{Nutzungsbedingungen}

Dieses Dokument steht unter folgender Creative Commons-Lizenz:

http://creativecommons.org/licenses/by-nc-nd/3.0/de/deed - Sie dürfen das Werk bzw. den Inhalt unter folgenden Bedingungen vervielfältigen, verbreiten und öffentlich zugänglich machen: Sie müssen den Namen des Autors/Rechteinhabers in der von ihm festgelegten Weise nennen. Dieses Werk bzw. dieser Inhalt darf nicht für kommerzielle Zwecke verwendet werden und es darf nicht bearbeitet, abgewandelt oder in anderer Weise verändert werden.

Mit der Verwendung dieses Dokuments erkennen Sie die Nutzungsbedingungen an.

\section{Terms of use}

This document is published under following Creative Commons-License: http://creativecommons.org/licenses/by-nc-nd/3.0/de/deed.en - You may copy, distribute and transmit, adapt or exhibit the work in the public as long as you attribute the work in the manner specified by the author or licensor. You are not allowed to make commercial use of the work or its contents. You are not allowed to alter, transform, or change this work in any other way.

By using this particular document, you accept the above-stated conditions of use.

\section{Kontakt / Contact:}

\section{peDOCS}

DIPF | Leibniz-Institut für Bildungsforschung und Bildungsinformation

Informationszentrum (IZ) Bildung

E-Mail: pedocs@dipf.de

Internet: www.pedocs.de

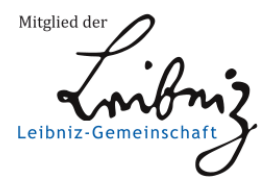




\section{IJREE}

International

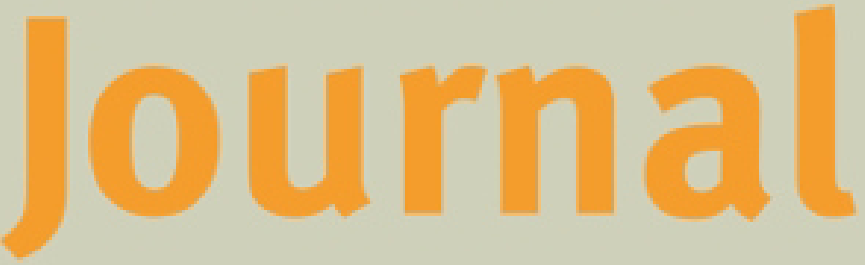

for

Research

on

Extended

Education 


\section{International Journal for Research on Extended Education, Volume 2/2014}

\section{Content}

Editorial

Charles Underwood \& Leann Parker

Introduction to the Main Topic:

University-Community Links: Collaborative Engagement in

Extended Learning

\section{ARTICLES}

Main Topic: UC Links: Collaborative Engagement in Extended Learning

Robert Lecusay

Building Zones of Proximal Development with Computer Games

in a UC Links After-school Program

Andrew Schuetze, Lorena Claeys, Belinda Bustos Flores \& Shannon Sezech

La Clase Mágica as a Community Based Expansive Learning Approach

to STEM Education

Marta Padrós, Sònia Sànchez-Busqués, José Luis Lalueza \& Isabel Crespo The Shere Rom Project: Looking for Alternatives to the Educational

Exclusion of Roma

Beatriz Macías Gómez-Estern, Virginia Martínez-Lozano \& Olga A. Vásquez "Real Learning" in Service Learning: Lessons from La Clase Mágica in the US and Spain

\section{FREE CONTRIBUTIONS}

Claudia G. Pineda \& Michael J. Nakkula

Dancing Ethnicity: A Qualitative Exploration of Immigrant Youth Agency

in an Ethnically Specific Program

Marianne Schüpbach

Extended Education in Switzerland: Values in Past, Present, and Future

Anna Klerfelt \& Björn Haglund

Walk-and-Talk Conversations: a Way to Elicit Children's Perspectives and

Prominent Discourses in School-Age Educare 
DEVELOPMENTS in the Field of Extended Education

Sang Hoon Bae

Values and Prospects of Extended Education: A Critical Review

of the Third NEO ER Meeting

\section{REVIEWS SECTION}

\section{Richard P. Durán}

Generating Transworld Pedagogies: Reimagining La Clase Mágica

Ed. Belinda Bustos Flores, Olga A. Vásquez, and Ellen Riojas Clark.

NewYork: Lexington Books, 2014

\section{AUTHOR INFORMATION}

Authors 
Free Contributions

\title{
Dancing Ethnicity: A Qualitative Exploration of Immigrant Youth Agency in an Ethnically Specific Program
}

\author{
Claudia G. Pineda \& Michael J. Nakkula
}

\begin{abstract}
This article addresses a conceptual gap in the Out-of-School Time literature by offering a framework to study the relationship between ethno-cultural components in programs focused on youth ethnic culture (ESPs) and ethnic identity development among longterm participants. Using qualitative methodologies, it examined the meaning-making of eight Colombian immigrant youth participants in ColDance, an after-school program focused on Colombian culture in Boston. Findings suggest ColDance played a powerful role in fostering a positive connection with youth's ethnic heritage crystallized in tangible dancing skills and specific knowledge about Colombian traditions. It provided and nurtured cultural brokers who eased youth's adaptation process. Further, it suggests that a performance-oriented program may expose youth to receptive audiences that function as social mirrors fostering positive self-concepts.
\end{abstract}

Keywords: After-school programs, ethnic identity, immigrant youth, Colombian youth, positive youth development.

Out-of-School Time (OST) programs are considered key contexts for the positive development of diverse children and youth (Vandell/Pierce/Dadisman 2005). Studies suggest that OST programs geared to minority children are most effective when they are culturally relevant. Although research on OST has made great strides in assessing the effects of different programming modalities, less is known regarding the effects of programs that are organized around youth ethnic culture. Some argue that programs geared to minority youth, including immigrant youth, have been too focused on the prevention of risk behavior rather than on the promotion of positive development (Villarruel/Montero-Sieburth/Dunbar/Outley 2005). In contrast, Ethnically Specific Programs (ESPs), an OST modality, aim to instill a sense of pride in immigrant youth ethnic background and maintain cultural traditions, which might not be valued in the larger society or represented during the school day. Through a qualitative study of Colombian immigrant youth, this article explores the mechanisms that may be involved in strengthening ethnic identities in long-term ESP participants, resulting in a conceptual framework for the study of ethno-cultural dimensions of ESPs. 


\section{Theoretical Framework}

\section{Ethnic Identity Development}

Adolescence is a critical period when identity is formulated in relation to past experiences, societal contexts, and the individual's expectations for themselves (Erikson 1968). This process is multidimensional in that identity develops simultaneously within different realms (e.g., gender or race/ethnicity). For immigrant youth, ethnic identity is a salient dimension, especially in contexts where there is contact with different ethnic groups.

Ethnic identity (EI) can be largely defined as the psychological sense of belonging to an ethnic group, based on either objective characteristics (e.g., language, food) or subjective ones (e.g., shared values, goals, and beliefs) (Suárez-Orozco/SuárezOrozco 2001). From a developmental perspective, Phinney (1990) argues that individuals go through three phases of ethnic identity formation: foreclosure/unexamined, exploration, and identity achievement. Foreclosure involves an unexamined sense of identity mostly based on others' opinions. During exploration, individuals delve into the personal meaning of ethnicity, which is often expressed by an increasing interest in their ethnic group's traditions and history and immersion in ethnic activities. The last stage of ethnic identity achievement is defined by a committed sense of belonging, positive feelings about one's ethnic group, and an appreciation for others.

A number of studies have demonstrated that an achieved EI is associated with various positive outcomes (Phinney/Horenczyk/Liebkind/Vedder 2001), such as high self-esteem, academic achievement, and overall wellbeing. Yet, the ultimate result can be affected by experiences of racism and discrimination, which may have a negative impact on youngster's sense of self and of others (Suárez-Orozco/SuárezOrozco 2001). According to Suárez-Orozco (2000) adults, peers, and the media become the social mirrors of immigrant youth; positive and negative images reflected back to them can lead to a sense of self-worth or the lack thereof, respectively. In a longitudinal study of 400 immigrant children, Suárez-Orozco and Suárez-Orozco (2001) found that children were aware of the negative and hostile images related to their ethnicity. They found that when negative messages about their participants' ethnic group were strong, children either internalized such images of themselves or exercised resistance.

The effects of negative stereotyping can be attenuated or intensified depending on the frame of reference immigrants use to interpret their current experiences. Louie (2006) argues that the dual frame of reference that informs identity formation can be either ethnically or transnationally oriented. An ethnically oriented identity compares personal experiences and achievements with co-ethnics in the context in which they have been incorporated into the U.S. and is more akin to a U.S.-made identity, whereas a transnationally oriented identity uses as a point of reference the experiences of co-nationals in the country of origin. In a study of college students in New York, Louie found that Dominicans, despite growing up in neighborhoods marked in part by high levels of poverty, violence, and low-quality schools, were more optimistic about their future in the U.S. than their Chinese counterparts, who were doing better academically (Louie 2006). Youth's dual frame of reference helped 
explain this paradox in that Dominicans compared themselves to co-nationals in the Dominican Republic who they thought were doing worse, whereas Chinese students compared themselves with co-ethnics in the U.S. who were presumably doing better than them. The transnational frame did not necessarily come from first-hand experience, but from transnational experiences and possibly parental transmission of transnational skills and ideas (Louie 2006).

Others have argued that symbolic or emotional transnational practices can serve as cultural resources that contribute to ethnic identity formation by providing a sense of belonging and pride in individual's ethnic background, especially in the face of discrimination and racism (Viruell-Fuentes 2006). ${ }^{1}$ In today's anti-immigrant climate, understanding how ESPs with ethno-cultural components might serve as buffers against negative messages is critical. Moreover, while the role of parents in orienting youth transnationally has been explored, less is known about the role of other practices that may do the same.

\section{Organized Activities and Ethnically Specific Programs (ESPs)}

Increasing numbers of children are engaged in organized activities during after school hours. ${ }^{2}$ As a result, the last decade has seen a growth of studies on the effects of participation that range from academic to socioemotional and health-related outcomes (Little/Wimer/Weiss 2008). Organized activities are more effective when developmentally appropriate, and adequately structured and staffed (Little et al. 2008). Relationships with caring adults and staff help youth connect to other cultural realms and provide role models or mentors (Rhodes 2004). Participation in organized activities is often voluntary, which makes youth more motivated to persist in activities they find engaging, safe, and structured (Borden/Perkins/Villarruel/Stone 2005). OST programs have the potential to promote and showcase youths' talents and competences, and foster a sense of self-efficacy, which contribute to the development of resilience or "patterns of positive adaptation in the context of significant adversity and or risk" (Masten/Reed 2002, p. 75). Specifically, dance, drama, and performance-based programs influence identity development by giving youth the opportunity to explore and experiment with different roles (Barber/Eccles/Stone 2001), to reconnect with their personal and cultural identities (Davis/Soep/Maira/ Remba/Putnor 1993), and to feel proud of their ethnic heritage (Ball/Heath 1993).

According to Masten and Coastworth (1998) promoting a sense of belonging and a positive connection with youth cultural heritage can be a powerful protective factor leading to positive adaptation in ethnic minorities. Researchers of out-of-school time (OST) have noted the importance of making programs culturally relevant, of incorporating cultural knowledge and materials that reflect the communities they serve, and of having trained staff, especially in diverse contexts (California Tomorrow 2003;

1 Transnationalism refers to the activities, loyalties and networks that connect immigrants with their country of origin, while still being incorporated into their host country (Guarnizo/Smith 1998). Emotional or symbolic transnationalism captures the affective and private aspects of transnational practices, such as the memories and attachments to the home country (Viruell-Fuentes 2006).

2 The use of the term organized activities is consistent with Mahoney, Larson, Eccles and Lord's (2005) definition, which refers to them as activities "that are not part of the school curriculum" and which are "characterized by structure, adult supervision, and skill building." (p. 4). Henceforth, we use organized, out-of-school, and after-school-, activities interchangeably. 
Harris 2007; O’Cadiz 2003). Yet, frequently culturally relevant components in OST are conceived as a means towards achieving other goals, such as preventing drug abuse, academic underperformance, or dropout in ethnic minority groups considered "at risk" (Pittman/Irby/Yohalem/Wilson-Ahlstrom 2004; Riggs 2006; Schinke et al. 1988). While addressing the needs of minority youth and preventing risk taking behavior are important goals, it is often the case that the strengths and assets of these communities are absent from programs' conceptions (Villarruel et al. 2005).

There has been a range of terms used to talk about programs that include cultural components relevant to the group they target, such as ethnic-oriented organizations (Borden et al. 2005), cultural enrichment activities (Pittman et al. 2004), cultural/ heritage programs (The Harvard Family Research Project), ${ }^{3}$ or community-based celebrations (Eccles/Gootman 2002). However, there is a lack of consensus of how to call these programs and how to conceptualize them.

The term Ethnically Specific Programs (ESPs) is introduced here to describe those that are targeted towards homogenous groups comprised of mostly first and second generation immigrant youth. They are focused on youth ethnic culture and on preserving expressive cultural practices, such as dance and music. ${ }^{4}$ Some examples include Ballet Folclórico for Mexican youth or Hmong Youth Pride (Chase/Clement 2000), a Minnesota-based program that teaches Hmong language and culture to youth. By emphasizing "ethnic" rather than "cultural," we intend to capture the contextual character of ethnicity as linked to processes of racialization (Blum 2007; De Genova/Ramos-Zayas 2003; Rumbaut 2009) and not to equate ethnic culture with culture, which renders the dominant culture as a point of reference. As such, referring to Colombians as ethnics reflects their minority status as part of the larger Latino pan-ethnic and U.S.-made category, with associated political and social implications.

ESPs are more clearly aligned with a developmental asset framework that conceives of youth's cultural traditions as a source of strength leading to positive adaptation (Benson 1997). The few existing studies of OST programs with an ethno-cultural approach have shown positive outcomes, including diminished problem behavior, improved attendance, and enhanced cultural identity and future-orientation (Harvey/ Hill 2004; Mason/Chuang 2001; Stevens/Owen 1998; Whaley/McQueen 2004). In these programs, both students and parents feel particularly connected with the ethnocultural component (Chase/Clement 2000; Shinew/Hibbler/Anderson 2000).

In this body of literature, studies focused on immigrant youth participation and associated outcomes are still scant (Waldfogel/Lahaie 2007). There is mixed evidence on whether Latino immigrant youth participate more or less in OST activities (Simpkins/O'Donnell/Delgado/Becnel 2011), and even less on those who sustain long-term participation. Community-based organizations seem particularly attuned to immigrant youth needs (Halpern 1999) and can be invaluable to these communities. Organized activities often provide role-models and mentors that support positive youth development (Roffman/Suárez-Orozco/Rhodes 2003), ease the transition to the host country (Diversi/Mecham 2005), allow for ethnic identity exploration,

3 The Harvard Family Research Project (HFRP) maintains a database of OST programs and bibliography, including cultural/heritage programs. http://www.hfrp.org/out-of-school-time.

4 Alba (1990) argues that ethnic groups decide which "positive heritage" is worth preserving. The expressive or explicit dimensions are often chosen, such as language, artistic expressions, or folklore. 
and promote self-regulation and feelings of self-worth (Riggs/Bohnert/Guzman/Davidson 2010).

\section{Why Do We Need a Framework?}

Several frameworks have been proposed to theorize the relationship between youth participation in OST and program outcomes (Durlak/Mahoney/Bohnert/Parente 2010; Fredricks et al. 2002; Vandell et al. 2005; Weiss/Little/Bouffard 2005). They have in common the inclusion of individual (e.g., gender, age, race/ethnicity), contextual (e.g., opportunities for participation), program (e.g., quality indicators), and youth participation factors (e.g., attendance, enrollment, and engagement). They also suggest the need to examine the interactions between contexts (e.g., family, school, peers, or neighborhoods) and propose mechanisms or theories that can help explain various effects (e.g., motivational, stage-environment fit, or identity development theories).

This study aims to complement these frameworks by providing an initial examination of the ethno-cultural mechanisms that may foster positive ethnic identities through long-term participation in ESPs, a subject that has received very limited attention. It adds to the existing frameworks by attending to the larger cultural context in which these programs are embedded that may depict ethnic youth as deficient or deviant (Villarruel et al. 2005) by considering the developmental processes specific to immigrant populations, such as acculturation (Simpkins et al. 2011); and by treating ethnicity as a contextually constructed dimension of identity that OST programs help shape, rather than as an individual and stable characteristic or variable. This framework was drawn from a qualitative exploration of the meaning Colombian immigrant youth ascribed to their participation in an ESP and the way they experienced the ethnically specific aspect of the program focused on dancing and performing Colombian folklore.

\section{Contextualization}

\section{Colombian Migration to the U.S.}

According to the 2005 Colombian Census, approximately 8\% (3.3 million) of the Colombian population lives abroad, mostly as a result of the country's worsening economic and political conditions. In the U.S., Colombians constitute the largest South American group and the fourth largest among the undocumented population (Guarnizo/Espitia 2007; U.S. Census Bureau 2003). The Colombian experience is similar to that of other Latin American groups, such as Central Americans, who also endured war-like circumstances. However, Colombians tend to be more geographically dispersed, arrive with higher levels of education, have more urban origins, and self-identify largely as "white" compared to other Latin American immigrant groups (Guarnizo/Espitia 2007; Guarnizo/Sánchez/Roach 1999; MacDonald/Carrillo 2010). Both the U.S. war against drugs, and later its war against terrorism, have marked the relationship between the U.S. and Colombia and contributed to the stigmatization of Colombians as violent and drug traffickers (Guarnizo/Sánchez 1998). 
The Ethnically Specific Program

ColDance (pseudonym) is an organization based in a large U.S. East Coast city that teaches Colombian folklore dance to youth. The mission of the group is multifaceted: to show the positive aspects of Colombian culture in response to the prevalent negative associations of Colombians with violence and drug-trafficking, to bring families together, and to keep children off the streets through dancing. At any given time, the group brings together 20 to 25 youths ages 11 to 25 , who rehearse traditional Colombian dances such as cumbia, mapalé, and joropo every Friday throughout the year. Their biannual show has become a popular event for the Colombian community throughout New England, drawing a crowd of approximately 800 people. ColDance also prepares for occasional performances in settings like schools, universities, festivals, or national celebrations. The group puts together elaborated lighting, costumes, scenery, backdrops, sound, and choreographies. This has been a long process whereby youth have been asked to do research on different aspects of Colombian culture and collaborate with professional dancers, musicians, and choreographers. Families often participate and support the shows. ColDance was featured as a community-based organization that supports the positive development of Colombian immigrant youth in an article by Roffman et al. (2003).

\section{Method}

This exploratory research consists of a case study of eight long-term participants in ColDance. Qualitative methods were selected because of the paucity of research on ESPs generally, and on long-term ESP participants specifically. The case study method was used because it is suitable for comparing and contrasting participants in the study while keeping them grounded in their relational and personal context (Yin 2014). A nuanced approach is critical for research of understudied ethnic groups, because it recognizes the complexity and diversity of experiences and perspectives within them (Offer/Schonert-Reichl 1992). This is the case of Colombians, who are often grouped with other Latino groups, a research practice that obscures the particular nature of the U.S-Colombia relations and the history of Colombians in the U.S.

\section{Participants \& Procedure}

The case study took place in three phases between 2000 and 2005. In 2000, all members $(n=25)$ filled out a survey exploring their motivation and engagement in the group and their awareness of how Colombians were perceived. In 2004, eight youths were selected for a follow-up study that employed a semi-structured interview to elicit in-depth responses about their immigration history, ethnic identity, and the meaning of participating in ColDance. In 2005, a follow-up study with the same group focused on a multicultural hypothetical dilemma. The larger study included one formal interview and several informal interviews with the director of the program. The analysis for this article draws mostly from the two first phases. While the data may seem dated, the mechanisms to which the analysis here point to are not. 
We used a purposeful sampling strategy (Maxwell 1996) to select eighth foreign-born youth (four males and four females) who were long-term (3 to 9 years) ColDance participants. Refer to Table 1 for demographic information. This type of long-term involvement is very uncommon as participation in out-of-school activities tends to decline during adolescence (Mahoney/Larson/Eccles/Lord 2005). However, for youth who remain committed, this study sheds light on how this involvement may shape their ethnic identities during their adolescent years.

We also included both current and former members (those who had left between 1 and 3 years prior to the interview), so that they could shed light on the reasons for discontinuing involvement with the group and the meaning of their involvement as they had gone on to different experiences. For them, some of the reasons for leaving included work and school demands that limited their time availability, entering a different developmental moment (e.g. parenting), becoming interested in other activities, or taking a particular professional trajectory that required different experiences.

The process of selection was based on the demographic information youth had provided during the first phase of the study and on more recent information the director provided about each member of this initial group. The ultimate selection tried to ensure that the study would draw insights from various perspectives (males/females and recent/former members) (LeCompte Preissle/Tesch 1993). It is important to note that these criteria limit generalizability to the extent that this study cannot shed light on those with less than 3 years of participation. It can be argued that this is a study of a self-selected group that already had positive identities, which motivated them to remain in the program. This is something that the study cannot rule-out; however, the focus here is on how long-term members perceived the different program components and what those components meant to them. Also, given the exploratory nature of the study about mechanisms that can promote positive youth development in the context of this program, there are limits to the generalization of the findings.

Most of the participants came from working-class families whose parents had either maintenance or cleaning jobs, and who were not college educated. While not all of the participants were undocumented, they all had been at some point. Participants had lived most of their time in the U.S. in working-class neighborhoods with large populations of Latin American immigrants and Colombians in particular.

To assess ethnic identity formation, we administered the Multigroup Ethnic Identity Measure (MEIM). A widely used measure created by Phinney (1992), the MEIM assesses (1) ethnic search (cognitive and developmental component) and (2) affirmation, belonging, and commitment (emotional component). It includes 12 items rated on a four-point Likert scale format. High scores indicate high levels of ethnic identity achievement and feelings of belonging. In a previous research with a college age sample, this measure had a reliability coefficient of .90 (Phinney 1992). The meaning they ascribed to their EI was further explored through a series of openended questions.

Interviews took place in participants' homes and lasted between 2 and 3 hours, during which consent forms were collected. The interviews were tape-recorded and transcribed, and conducted in the language in which participants felt most comfortable. All except one responded in Spanish. The first author collected all the data for this study. 
Table 1. Demographic Information, ESP Participation, and Overall Migratory Experience

\begin{tabular}{|l|l|l|l|l|l|}
\hline Pseudonym ${ }^{1}$ & $\begin{array}{l}\text { Age at Time } \\
\text { of Interview }\end{array}$ & $\begin{array}{l}\text { Age range of } \\
\text { Participation }\end{array}$ & $\begin{array}{l}\text { Years in } \\
\text { ColDance }\end{array}$ & $\begin{array}{l}\text { Age upon } \\
\text { Migration }\end{array}$ & $\begin{array}{l}\text { Overall Migratory Expe- } \\
\text { rience }\end{array}$ \\
\hline Carlos & 24 & $15-24$ & 9 & 10 & $\begin{array}{l}\text { Language was hard. } \\
\text { Didn't feel alone be- } \\
\text { cause of his family. }\end{array}$ \\
\hline Oscar & 24 & $15-24$ & 9 & 13 & $\begin{array}{l}\text { Family reunification } \\
\text { was hard. Felt disori- } \\
\text { ented. }\end{array}$ \\
\hline Pablo & 22 & $13-22$ & 9 & 8 & $\begin{array}{l}\text { Things were different. } \\
\text { People were walled-in } \\
\text { (encerrada) and not } \\
\text { friendly. }\end{array}$ \\
\hline César & 24 & $17-22$ & 5 & 7 & $\begin{array}{l}\text { Given that he was so } \\
\text { young, the change was } \\
\text { radical, but not so hard. }\end{array}$ \\
\hline Angela & 20 & $11-17$ & 6 & 5 & $\begin{array}{l}\text { Because she migrated } \\
\text { at an early age and } \\
\text { was more American- } \\
\text { ized, she felt judged for } \\
\text { not being Colombian } \\
\text { enough. }\end{array}$ \\
\hline Carmen & 25 & $15-21$ & 6 & 12 & $\begin{array}{l}\text { Language shock was } \\
\text { horrible. Worst experi- } \\
\text { ence ever. }\end{array}$ \\
\hline Lina & 26 & $18-25$ & 7 & 15 & $\begin{array}{l}\text { Traumatizing, frustrat- } \\
\text { ing. }\end{array}$ \\
\hline Sonia & 20 & $15-18$ & 3 & $\begin{array}{l}\text { Terrible, felt very lost } \\
\text { like starting from zero. }\end{array}$ \\
\hline
\end{tabular}

${ }^{1}$ Pseudonyms are used to protect interviewees' confidentiality.

\section{Qualitative Analysis}

We used both data-driven and theory-driven analytic approaches (Miles/Huberman 1994) to answer the research questions. Theories of OST, ethnic identity, and adolescent development informed the thematic analysis. Atlas.ti, a qualitative research software (Lewins/Silver 2007) was used for coding. The coding process involved developing open codes, including program components and how youth made sense of them. A process of code aggregation that pointed to more abstract categories followed (Boyatzis 1998; Strauss/Corbin 1990). These more abstract categories are reflected in the mechanisms and functions of the framework proposed here. There were several iterations of data analysis to ensure reliability of coding and achieve theoretical saturation. To keep youth responses contextualized in their personal and immigration experiences, we constructed profiles for each participant that summarized different data sources. We used matrices (Miles/Huberman 1994) to facilitate comparison across cases (Miles/Huberman 1994), constructed logic diagrams (Strauss/Corbin 1990) to assist with theory building, and wrote integrative and analytic memos (Nakkula/Ravitch 1998) to build and integrate our interpretations. 
Even though retrospective studies are subject to memory recall bias (Thomsen/ Brinkmann 2009), our focus on youth's interpretations of their long-term participation in ColDance and what they suggest about the possible mechanisms involved in such participation justifies and even requires the use of retrospective accounts (Scott/ Aldwin 1998). Further, we subscribe to the view that present interpretations of past events are not merely accurate or distorted accounts that need to be captured reliably, but rather that they are integral to individuals' sense of self and identity (Flyvbjerg 2006).

Throughout the data collection process, one of the authors drew on her role as both an insider and an outsider. Her insider status derived from being, like most ColDance participants, a first-generation Colombian immigrant. Further, she had been a volunteer for the group for three years prior to carrying out the study. She developed relationships with the respondents during that time, which facilitated access to them, fostered some degree of openness on their part, and allowed her to have some shared understanding of their experiences, all of which allowed for a more indepth study (Flyvbjerg 2006). That she was an "insider" also equipped her with the cultural skills necessary to study this population (Ojeda/Flores/Meza/Morales 2011).

At the same time, the fact that she had migrated to the U.S. as a young adult, and that her only educational experiences in the U.S. were as a graduate student, identified her as an outsider. Hence, she was particularly attentive to issues of reflexivity and to the risk that some of her interpretations could be misguided based on assumptions of shared experiences. To ensure study trustworthiness, we shared the analysis process with an interpretive community of qualitative researchers (Morrow 2005), searched for discrepant evidence across the different data sources and across cases, which aided in the triangulation of evidence, and checked for alternative interpretations in case we were limiting our analysis to our framework of understanding (Flyvbjerg 2006; Maxwell 2005; Nakkula/Ravitch 1998).

\section{Findings}

We first discuss youth's awareness of how Colombians are perceived. Next, we show how despite the negative views on Colombians, youth in this sample display positive ethnic identities. We then introduced the thematic analyses that theorized ESP mechanisms involved in positive identity development.

\section{Mixed Perceptions of Colombians}

To assess whether ColDance youth were aware of negative messages about them as Colombians, in the 2000 Survey, youth completed the following sentence: "Other people think Colombians are " 5 Consistent with Suárez-Orozco and SuárezOrozco's findings of the children's awareness of the existence of negative images, 17 of 21 responses $(76 \%)$ included negative words like "traquetos" (slang word for drug-dealers), "violent," "killers," or simply "bad", seven responses also included

5 This question was adapted from the Harvard Longitudinal Immigration Adaptation Program. 
positive attributes (e.g., good people). Only four responses contained only positive attributes. These messages were explored more deeply later in the interviews where respondents discussed both positive and negative stereotypes associated with Colombians. Positive stereotypes include being good students, speaking good Spanish, being proud of who they are, or doing good things related to arts (e.g., Shakira). Despite these positive aspects, they all talked about being stereotyped as drug-dealers, violent, cheaters, undocumented, or terrorists. They attributed the prevalence of negative images associated with Colombia to the media and, sometimes, to the few Colombians "who have brought the bad reputation to others." Despite the negative associations, all interviewees felt proud of being Colombian and none mentioned feeling ashamed of their ethnicity. They often articulated their participation in ColDance as motivated, in part, by the need to represent Colombia in a positive light, which reveals their awareness of the processes of racialization in the U.S. (Rumbaut 2009) that depict Colombians negatively.

\section{Positive Ethnic Identities}

Despite youth's awareness of the stigma associated with Colombians, youth in the study displayed very positive ethnic identities (EI), with seven out of the eight youth scoring 3.4 or higher on the overall EI scores. From a developmental perspective, high scores for youth in their early to mid 20's are not entirely surprising considering that they should have gone through the process of identity exploration during adolescence. However, these scores are above average for the college sample studied by Phinney (1992), whose mean scores on EI were 3.04 compared to 3.5 for this sample. These high scores are noteworthy because, according to the MEIM, they reflect that these youths have shown an interest in learning about their ethnic group, have thought about the meaning of their ethnicity to them, and have a secure sense of an ethnic self. That their participation in an ESP focused on Colombian traditions, folklore, and culture probably contributed to strengthening their EI and provided opportunities for identity exploration during their adolescence.

\section{Framework: ESP Components, Mechanisms, and Functions}

Thematic analyses of interview data suggested important program components for long-term participants, the functions of those components, and the mechanisms underlying these functions that may have played a role in positive identity development. Major mechanisms included supportive social networks and opportunities to experience success as a result of hard work and practice, the learning of specific knowledge about youth's ethnic heritage, and the provision of a legitimate public space where youth performances of their ethnic heritage was valued. Figure 1 graphically illustrates these findings. 
Figure 1.

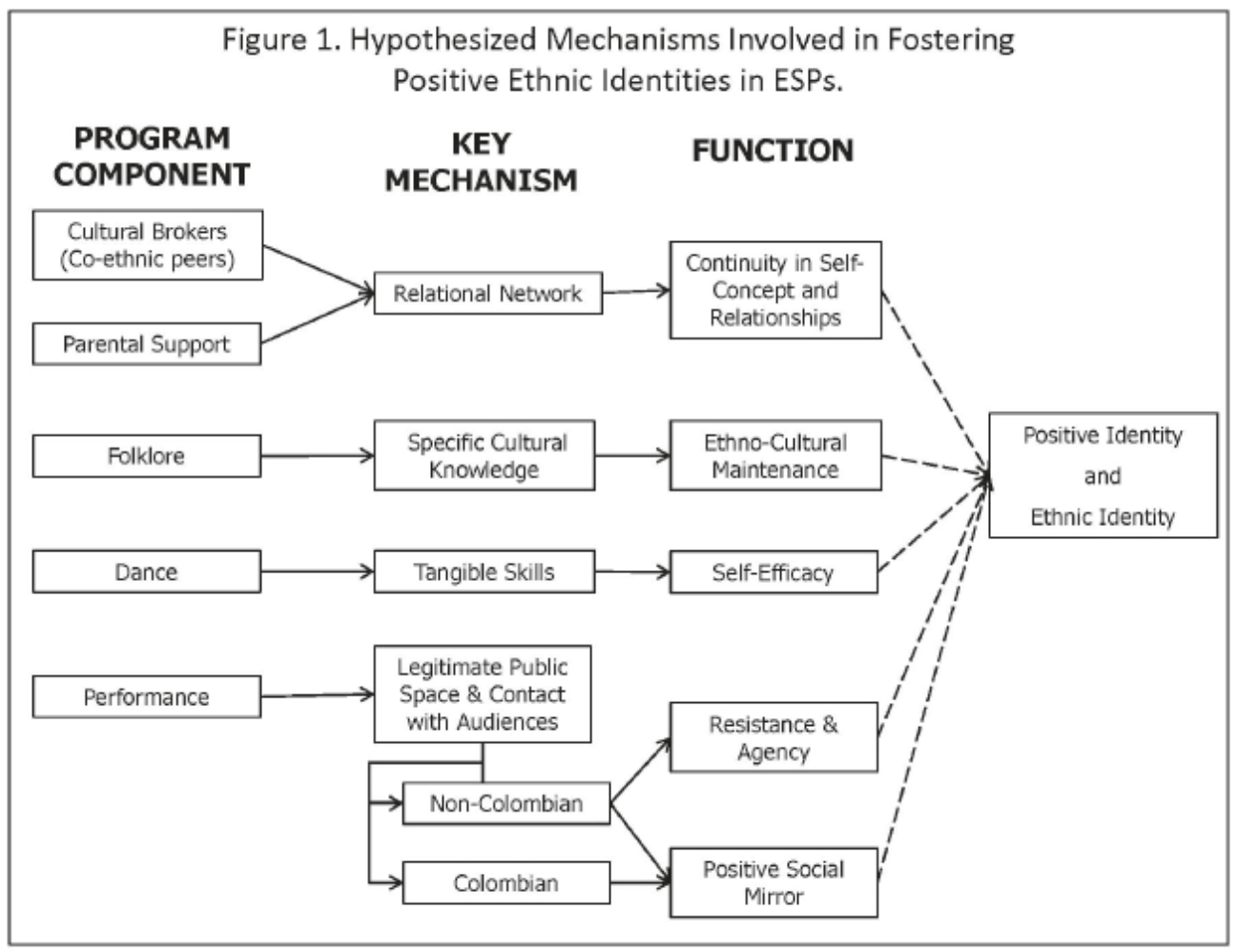

Source: Pineda/Nakkula

Continuity in Self-Concept and Relationships: Doing What I Used to Do, Being What I Used to Be

Youth indicated that ColDance provided a sense of continuity in relation to activities and relationships severed by the process of migration. A social network of peers and caring adults, particularly the director, who felt connected by their common ethnic background promoted this continuity. Co-ethnics served as cultural brokers who helped youth engage in activities that they used to do before migrating and that were also available in the host society.

A cultural broker is typically a bicultural actor that serves as a link between the mainstream and the ethnic culture (Gentemann/Whitehead 1983). These individuals usually come from the same background as youth, are able to "translate" cultural norms, and are considered role models by ethnic communities who deemed them successful in the mainstream culture, such as teachers or counselors (Gentemann/ Whitehead 1983). Lina explains how she thought she "was like a role model for others who joined, because many people used to say I want to dance like [her]." In ColDance both the director and long-term immigrant youth were admired by others, because, they danced well, had attended college (for some in spite of lacking immigrant documentation), and were examples of positive adaption for their community. 
This function was particularly important in the face of the multiple losses they had experienced.

[Kids in ColDance] were the ones who taught me to love being here, to be able to have a life again here; not feeling like 'okay, when am I going to return to Colombia?'... [they] taught me that there was more, there were movies, there were parks to enjoy, that there was a school where you could have cultural activities. I mean, I said 'okay, I can do the same things here that I used to do [in Colombia].' Sonia

ColDance cultural brokers made accessible information that helped youth navigate the new context, including connecting youth with engaging activities similar to the ones that defined who the participants were before migrating. Youth also expressed the need for continuity in relation to feelings of inadequacy and ColDance became a "transitional space" (Noam/ Biancarosa/Dechausay 2003), within which the navigation across different domains, such as school, work, and family was facilitated. While they conceived of those domains as separate or compartmentalized, ColDance seem to ease the transition into each of them and became a space that was familiar and supportive. Following are two examples:

Six years of constant practice [made me last that long], that you would start the week, school, work, laundry, and you couldn't wait to get to Friday to go and say 'What's up, what did you do, how was your week? Tell me about this, about that person.' Carmen

As a recent immigrant you lose your friends in Colombia, the group of peers at school, the neighborhood, your cousins, all the people you were in contact with [...] By being in a Colombian group, you don't have an attitude anymore about school, [not speaking English], and this country. In ColDance, doing all those Colombian dances and [hanging out with friends] was like finding a little piece of Colombia in them. Oscar

For Oscar being in ColDance was a way of establishing a sense of continuity to counter the disruption caused by migration and for Carmen it was a key transitional space between school and home, one that was consistent and she could count on. Colombian peers helped them connect to something they valued and missed, especially in the larger context of their lives where important demands were placed on them, such as learning English and adapting to a new school.

Parental Support. Feelings of dislocation and loss of familiar networks often contribute to immigrant acculturation stress. Yet, feelings of continuity can serve as a protective factor (Beardslee 2002). This is especially true for youth whose families experience financial struggles, where parents are not available to help children in their transition because they may be working several shifts to make ends meet, or having difficulties themselves in the adaptation process (García-Coll/Magnuson 1997). Several respondents, specially the girls who migrated as early adolescents, expressed that at some point they wanted to return to Colombia because they were unhappy. This idea of returning was more a wish than a realistic expectation, because their parents, who had undergone enormous sacrifices to bring their children to the U.S., were not supportive of having them go back to Colombia. Parents often worked extended hours and youth had to adopt adult roles to help their parents, which further constrained their abilities to engage in after-school activities. Lina felt especially frustrated and limited because she had to take care of her brother after school while her mother worked until she joined ColDance. 
It's funny, at the time I got involved in ColDance, I was thinking about going back to Colombia. I was fed up... I couldn't do what people my age did... I was so depressed for not having friends and school was boring, so I thought [joining ColDance] would be a good way to go back to the way I used to be: concentrating in music, having friends with similar culture and beliefs as mine, or at least from the same country. Lina

Similar barriers to participation, such as home chores or babysitting, among Latinas have been found in other studies (Borden et al. 2005). However, according to these youth, having a responsible adult as the director and an all-Colombian group helped parents make the decision to support them. In fact, Lina's mother and stepfather decided to change working schedules so she could participate in the group. Interviewees also referred to parents feeling proud that their children were engaged in something that demonstrated the positive side of Colombia, were doing productive activities, and were not out on the streets engaging in risky behavior. Oscar talked about each of their mother's views on their involvement in ColDance.

She went to all the performances. She related to the mothers of the other participants a lot. They had parties, a lot of parties. So, my mom was also part of ColDance's moms, which was a separate group. Oscar

But parents and relatives were not only supportive; they also played instrumental roles in ColDance, for example the group started rehearsing in the basement of one member's uncle; parents were chaperones on field trips; one mom did the flower arrangements for one dance; and parents were the main promoters of each show. At the cultural level, the activities in which youth participate are very important, because it is through them that cultural values are transmitted (Weisner 2002). By strengthening youth's social support network based on a common ethnic heritage, ColDance seem to have become one of those activities that were desirable to youth and perceived as consistent with parental goals.

\section{Ethno-Cultural Maintenance: Learning about Colombian Folklore}

ColDance allowed members to keep a connection alive with Colombia by providing them with opportunities to learn new information in terms of traditions, costumes, music, history, and dances. As mentioned earlier, resilience studies have recognized the protective role that being in touch with cultural traditions has played for ethnic minorities since this knowledge can become a source of pride (Benson 1997). This is illustrated in Carmen's response to how she felt dancing folkloric dance.

[Dancing Colombian folklore] was very special... when I joined ColDance the only things I knew how to dance were salsa and merengue and things like that. I might have heard of the Sanjuanero, which is the most traditional one, but I had never heard of a joropo, neither a guabina, or a cumbia, or any of those dances... It was super, to be able to learn something that I thought I would probably never hear, see, or learn. Carmen

Perhaps Carmen would have learned those traditional dances at school had she stayed in Colombia; she certainly would have heard of them somewhere. Yet, being exposed to this aspect of Colombia that she didn't know, all while living in the U.S., gave her a deeper understanding of her cultural heritage. In effect, learning about Colombian culture came from active engagement by youth, who were asked to do research about Colombian traditions and were put in creative roles that included cho- 
reographing dances and designing costumes and sets. Having a voice in the creative process gave youth the opportunity to make personal connections to their cultural traditions.

[ColDance] was very different [from other dance groups]. 'Go do research in any book, find things about this or that city in Colombia, look for the things they did in La Guajira [Colombian northern region].' Carmen

By focusing on Colombian history, ColDance oriented youth's ethnic identity transnationally so that meaning of their ethnicity was not only understood in relation to how Colombians were perceived in the U.S. (ethnic orientation), but also in relation to Colombian history from their native country's viewpoint (transnational orientation). This aspect of ColDance was particularly valuable because, most of them had not visited Colombia since they migrated due to their lack of documentation.

Cultural Anchors of Conflicted Identities. When youth talked about feeling proud of being Colombian, they often incorporated the cultural learning taking place in ColDance into their identities. This was particularly true for Angela, who came to the U.S. when she was five and, of the interviewees, was perhaps the most "Americanized." She preferred speaking English, most of her friends were "white," and she was dating a "white" American boy. Although she described herself as "one hundred percent Colombian," during the interview it became evident that she felt conflicted between her Colombian and American values. This was further exacerbated by instances when she was accused of being a "fake" Colombian by other Colombians outside ColDance, which greatly distressed her.

When you are outside of ColDance, when you are, like, in high school, people just look at you making fun, and I'm, like, 'I think I'm even more Colombian than you are, cause I'm out there showing people where I'm from, and you are just making fun of people that are not.' [...] Instead of making fun of them, show them why you are so proud of who you are. And that's what ColDance did. Angela

Her participation in ColDance functioned as a shield against the accusations about the authenticity of her ethnic membership. ColDance was very important to her because it allowed her to feel proud of being Colombian and connected to a group of Colombians who accepted her, despite her degree of acculturation.

\section{Cultural Self-Efficacy and Talent: "I Can Dance."}

Studies of human agency describe the kinds of belief systems that can mobilize people to act, such as a sense of self-efficacy (Bandura 2001). Self-efficacy is very important not only because it can influence the choice of and persistence in challenging activities, but also because it can have a positive influence on an individual's wellbeing. Self-efficacy is promoted by four main mechanisms: (1) observation of others, (2) successful experiences as the result of practice and training, (3) persuasion or what others say we can or cannot do, and (4) positive affective responses associated with successful experiences (Maddux 2002). We argue that all of these mechanisms were in place in youth's experiences of dancing and performing in ColDance. Newcomers observed more experienced dancers in solo performances and were often taught by them. Their accounts reflect how they derived motivation to continue practicing from seeing the positive results of such effort and from seeing others' response 
to their performances. Here Pablo describes an experience of success and associated positive emotions:

We danced, so we said let's continue dancing, and also I saw that I danced once and it went o.k., and I didn't get like, 'oh, no I don't want to do it,' but instead like I said 'Wow I did it. I did it!' So then like I demonstrated to myself that I could do it, so then I said: 'let's do it again, let's do it! So that's why I stayed. Pablo

As Pablo's response illustrates, in ColDance experiences of success given by practice and various performances created a dialectical process whereby self-efficacy became both a source and the result of their involvement in ColDance: the more they practiced and performed, the more confident they became about their capacity to do it well; and the more confident they became, the better they mastered that skill by practicing. Dancing and performing had far reaching consequences for several ColDance participants. Pablo, for example, in addition to attending college, became a semiprofessional dancer who complemented his income by teaching Latin dances in nightclubs. This additional source of income and recognition became critical given his lack of documentation.

Dancing as a tangible skill and understood as a talent allowed these youths to feel proud and received recognition from it. As mentioned earlier, developing a talent valued by the self and by society constitutes a protective factor in the midst of risk factors (Masten/Reed 2002), including migration. Yet, to dance well, youth demonstrated incredible commitment to practicing several times a week and, sometimes, during the weekends when their friends outside of ColDance where engaged in other leisure activities. This commitment contrasts with the negative ways in which immigrant children, particularly undocumented youth, are portrayed in the media and in the political discourse as unmotivated and disengaged. Their contribution to bettering themselves, their communities, and making their parents proud often goes unmentioned.

\section{Resistance and Agency: Teaching about Colombian Culture}

The value of folklore was understood by youth within their larger context wherein ColDance became a means of changing the negative Colombian image by teaching non-Colombians about the positive aspects of their culture. An opportunity afforded by having many performances take place with non-Colombian audiences (in schools, universities, elderly homes, the annual show, etc.). Thus, ColDance constituted for these youngsters a vehicle of cultural resistance, and, more specifically, agency, in the sense that they were contesting the negative Colombian stigma by enacting a positive cultural representation of Colombia and of Colombian youth.

ColDance [made us] proud of who we are. They went out and showed people, you know, we danced for American people who didn't know that Colombia was more than drug-dealing and kidnapping people. There is this cultural side that is beautiful. We are not just ... drug-dealers and stuff like that. [We are] deep people who have values, who respect our culture, who are proud of our culture, and who express that every day. Angela

This passage is particularly illuminating for what it says about youth engagement in a more productive resistance, one that contrasts with other strategies that lead to the detriment of the stigmatized youth, such as school disengagement (Ogbu/Simmons 
1998). This resistance consists of offering alternative cultural representations and attributes based on folklore, traditions, and positive youth behavior that can prompt the audience to examine their preconceptions. Ultimately, the goal is to broaden people's perceptions of Colombians. Carlos explains the meaning of folkloric dance with respect to a more agentic resistance.

Dancing Colombian folklore is more cultural [compared to modern dances], in that it is focused more on Colombian culture, and on teaching and educating people about it. Carlos

Carlos response and the overall group mission focused on changing Colombia's stigma illustrate how ColDance fostered an ethnic-oriented identity. It made youth aware of the particular ways in which they are positioned in the racial/ethnic U.S. landscape, wherein Colombians, and Latinos for that matter, have a social lower status (De Genova/ Ramos-Zayas 2003; Rumbaut 2009) that they refuse to accept. As reflected in youth's narratives, the power of ColDance in countering negative cultural stereotypes relies on promoting a sense of agency, whereby youth feel they are indeed creating new representations of what Colombia is about to those who are more familiar with its negative aspects. Because stigma constitutes a threat to the person's self-esteem, interventions that counteract those negative messages are crucial.

\section{Positive Social Mirror: Loving to Perform and Performing to be Loved}

One of the components of ColDance that youth felt it was most influential related to offering them the opportunity to perform for an audience. As such, public performances functioned as a positive social mirror that countered the negative views reflected back to them in other contexts. Performing to Colombian and non-Colombian audiences was critical for promoting a sense of self-worth derived from their positive interactions with the audience.

There were times when, for example, we went to a festival in Pasadena; oh, I'm never going to forget this! And over there it was the first time we danced the salsa. And I remember that that day the people were even asking for our autographs. In the program they had put our pictures and we were like signing autographs, I could not believe it... Can you imagine? César

The audience's applause and reactions embody recognition by the other, the mirror. Through the audience, youth recognize themselves positively beyond the more personal context of relationships. This process can be both personal and impersonal: impersonal, in that the audience does not necessarily know the performers - their histories, their personalities, their unique selves; and personal, in that the applause is aimed at the performers directly, at their dances, their movements, their expressions. The impersonal aspect of performance can be especially positive for youth who have a negative self-image of themselves in other domains. This mirroring process is closely connected to their ethnic background given the focus on Colombian folklore. According to Oscar the most meaningful part of participating in ColDance entailed,

feeling appreciated by the public... wearing a hat, an alpargata (espadrille), a machete, that's what I liked most, but what I'm always going to remember is the affection of the public when they applaud you. Oscar 
Getting a positive response from enacting Colombian history and folklore, as Oscar described, is a very visible way in which others acknowledge and value youth's cultural heritage. Another dimension of the social mirror came from the role youth thought ColDance played for the members of the Colombian community, who attended the performances. These youth described how many Colombians, due to financial constrain or lack of immigration documentation, do not return to Colombia for long periods of time and long for familiar places, music, and cultural activities.

Culture is something we have to maintain, including the [Spanish] language and the customs... so we were trying to maintain that. When people saw us performing a Sanjuanero or a Cumbia it gave them the shivers, because it had been a long time since they saw them last, not even on T.V. Oscar

For other participants, including Oscar, contributing to maintain Colombian culture among their co-nationals through ColDance was extremely important. A Colombian audience is very receptive to their performances and this is not just out of an obligation to support a group of children engaged in a positive activity. Youth narratives revealed that for Colombians in the audience, their histories, hopes, and fears intersect with those of the young dancers on the stage. This encounter brought about selfreflection and understanding in both parties, and the intensity of the experience was heightened through the ethnically specific content of the performance. The audience "gets the shivers" and cries and youth reflect on who they are, becoming more proud of their own culture. Participation in ColDance, as described by interviewees, lead to the co-construction of identities wherein others - Colombians and non-Colombians, peers and adults alike - play a role.

In ColDance I noticed that [Colombians were proud]. 'Cause you go to these shows, people would be just ecstatic that they were meeting these kids who were dancing, and being proud of being Colombian, and you know they loved it. That even though you are a kid you are still proud of where you are from. So I loved it. Angela

Just as importantly, ColDance offered a legitimate space of recognition wherein those without immigration documentation could inhabit. There are few spaces where undocumented youth are acknowledged or where their right to participate is not questioned. They talked about painful experiences related to their migratory status, such as being turned away from jobs or opportunities to which they qualified otherwise. However, not once during their telling of their experiences in ColDance did they talk about their migratory status as an impediment for participation. We posit that ColDance's public performances provided the space where youths' immigrant documentation status became less consequential and where, instead, they could still gain legitimate recognition for their personal and group achievements as Colombian dancers.

\section{$4 \quad$ Discussion and Conclusions}

Ethnically specific programs are a significant, but understudied OST modality. This research provides an important advancement to the understanding of ESPs by offering a framework that outlines possible functions and underlying mechanisms that 
may contribute to positive identity development among long-term participants. In light of youth's narratives, the analyses suggested the following: First, while respondents were well aware of the negative stereotypes associated with Colombians, this negativity did not seem to affect the positive feelings associated with their ethnicity. In fact, those same stereotypes contributed to their motivation to actively participate in ColDance in order to change them. This is probably not unique to the Colombians studied here. Programs like ColDance are common among communitybased youth organizations that articulate their mission in relation to negative and hostile environments that depict the youth they serve as deficient. Yet, little attention has been paid in the OST literature to this ethno-cultural dimension. Contributing to this gap are the ways in which program modalities tend to be assessed, which fail to differentiate between ESPs and more general arts or performance programs. If we are to understand how youth's ethnic background plays a role in OST participation, both the type and content of their activities, as well as their awareness of how people from their ethnic background are perceived need to be examined.

The findings also bring to the forefront the ways in which ColDance addressed some of the challenges experienced by these immigrant youth, such as the need to experience a sense of continuity in the face of multiple losses. Providing cultural brokers who connected newcomers to different resources and activities that were integral to their sense of self before migrating proved invaluable. ColDance also seemed to have strengthen youth's relational networks by connecting them with other Colombians in the community. Consistent with the limited research on ESPs, youth reported that the ethnic focus facilitated parental support. Parents became invested in ColDance and were proud of their children's participation. Given that parental support for youth OST participation is often necessary, especially, among immigrant and low-income youth (Simpkins et al. 2011), examining this ethno-cultural mechanism from the parents' viewpoint needs to be further studied. However, this study does shed light on how ESPs may support positive adaption and possibly lessen the acculturation stress that can be experienced in the process of migration.

While a causal connection between the positive identities and participation in ColDance cannot be established, ColDance focus on their ethnic culture may have allowed them to explore their ethnicity in a safe space. Doing so during a developmental period characterized by questions about who they are can contribute to achieved identities anchored on specific knowledge about their cultural background and supported by real talents. This can be particularly valuable for youth, like Angela, whose conflicted identities can make them vulnerable to feeling that the ethnic aspect of their identity is in question as a result of rapid acculturation. In this sense, this article sheds light on how ethnic identities might be shaped through long-term participation. However, it is limited on whether these mechanisms may have led to this long-term involvement or on clarifying whether this was a self-selected group. However, that this program was focused on Colombian culture may have contributed to the particular ways in which these youths conceived of their identities as Colombians.

ColDance also contributed to fostering both ethnically and transnationally oriented identities in these youth. Youth motivation to respond to the negative stereotypes revealed their awareness of the processes of racialization, wherein Colombians are constructed as ethnic minorities in the U.S. associated with drug-trafficking and violence. At the same time, ColDance allowed them to be transnationally oriented 
by promoting a personal connection to Colombia's history and traditions. This supports Louie's (2006) argument that symbolic and emotional transnationalism do not require individuals to engage in activities, such as traveling to the homeland. ESPs may play a role in making youth be rooted in their homelands, but buffer the effects of negative stereotyping where they live.

Youth identities were not necessarily without complexity. They not only felt very positive about their ethnicity, but were also critical of the ways in which Colombians in Colombia and in the U.S. can be classist, racist, or close-minded. Hence, conceiving of ethnic culture as a source of strength does not mean that it should be treat it uncritically and regarded as a static and essential trait held by individuals or entire ethnic groups, and good in all respects. Instead, ESP practitioners should encourage youth to examine their cultural background with critical lenses and draw on the positive aspects only. Not doing so, may actually hinder positive intergroup relations where asymmetries exist fueled by nativistic views of their own ethnicity. In fact, some youth did conceive of their Colombian ethnicity in a more static way and had difficulty allowing non-Colombian youth into the group when the group opened up to non-Colombians after the second phase of the study took place (see Pineda 2014 for an extended discussion of ethnic boundaries in the context of this ESP).

Research on ESPs would benefit from conceptualizing ethnicity and ethnic identity as "works in progress" that are deeply shaped by the contexts in which youth are embedded. As illustrated here, youth participation in this ESP informed the way they felt about their ethnicity by instilling a sense of pride in their ethnic background and cultural traditions.

Given that the goal of the study was not to generalize to other populations, the findings should be interpreted cautiously. The focus on long-term participants opens questions about youth who did not engage in the group and their reasons for leaving early in the process. While the sampling strategy aimed at including diverse perspectives, it was not intended to be a representative sample either, so the findings should not be generalized to all youth in these types of programs. Future studies would benefit from longitudinal approaches to the study of long-term participation. The framework proposed is a first step towards focusing attention to the possible mechanisms and ESPs ethno-cultural components that contribute to long-term involvement and the development of positive ethnic identities. This framework can guide large scale studies of ESPs to replicate these findings among other ethnic youth.

Doris Sommer argues that "where structures or conditions can seem intractable, creative practices add dangerous supplements for intervention and locate room for maneuver." (2006, p. 3.) ESPs afford legitimate spaces - often among the very few wherein disenfranchised immigrant youth receive positive recognition. Youth public performances create the "wiggle room," as Sommer would say, where audiences are prompted to revise their preconceptions of Colombians and suspend their views on undocumented youth. Even if unintended, the audience contributes to the construction of strong positive identities, and youth exert their agency by unapologetically inhabiting that space. To conceive of these youth's performances as agency and resistance is to hold the mirror back to the same audiences that can be at times judging of their immigration status. Youth agency takes, literally, center stage.

But while the benefits of ESPs cannot be overlooked, neither can they be overstated; for youth are immersed in a larger context of long-entrenched structural barriers. Even though all the respondents graduated from college or where attending 
one, some of them, especially the undocumented ones, talked about shattered professional aspirations (e.g., getting a scholarship to later find out it was withdrawn or not being able to get a license to practice their profession) and the very realities of having limited opportunities. Without structural changes, ESPs will be limited at best in supporting this youth in an increasing anti-immigrant context that refuses to acknowledge both the talents they have worked hard to develop and the ways they have remained committed to bettering themselves and their communities. Educators and policy-makers do well aligning their efforts to change the conditions in which these youth make the transition into adulthood.

By focusing attention on a program that assumes youth ethnic heritage is worth preserving, rather than dwelling on what youth are lacking, we aim to reframe the discussion about the role that ethnic culture plays in OST programming and theorizing. Consistent with a body of literature detailing the positive effects associated with achieved ethnic identities (Phinney et al. 2001), youth's connection to their cultural heritage should be seen as desirable and necessary for positive adaptation in and of itself. We believe that programs that see youth's cultural heritage in this manner are more closely aligned with positive youth development principles that assume all youth have strengths and the potential for healthy development (Lerner/Dowling/ Anderson 2003).

\section{References}

Alba, R. (1990). Ethnic identity: The transformation of White America. New Haven: Yale University Press.

Ball, A./Heath, S. B. (1993). Dances of identity: Finding an ethnic self in the arts. In: S. Brice Heath/M. W. McLaughlin (Eds.), Identity and inner-city youth: Beyond ethnicity and gender. New York: Teachers College Press.

Bandura, A. (2001). Social cognitive theory: An agentic perspective. Annual Review of Psychology, 52, 1-26.

Barber, B., L./Eccles, J. S./Stone, M. R. (2001). Whatever happened to the jock, the brain and the princess? Young adult pathways linked to adolescent activity involvement and social identity. Journal of Adolescent Research, 16(5), 429-455.

Beardslee, W. R. (2002). Out of the darkened room. When a parent is depressed: Protecting the children and strengthening the family. Boston: Little, Brown and Company.

Benson, P. L. (1997). All our kids are our kids: What communities must do to raise caring and responsible children and adolescents. San Francisco: Jossey-Bass.

Blum, L. (2007). Race, national ideals, and civic virtue. Social Theory and Practice, $33(4), 433-556$.

Boyatzis, R. E. (1998). Transforming qualitative information: Thematic analysis and code development. Thousand Oaks, CA: Sage.

Borden, L. M./Perkins, D. F./Villarruel, F. A./Stone, M. R. (2005). To participate or not to participate: That is the question. New Directions for Youth Development (105), 33-49. 
California Tomorrow. (2003). Pursuing the promise: Addressing equity, access, and diversity in after school and youth programs. Oakland, CA: California Tomorrow.

Chase, R. A./Clement, D. (2000). Hmong youth pride: Outcomes evaluation summary St. Paul, MN: Wilder Research Center.

Davis, J./Soep, E./Maira, S./Remba, N./Putnor, D. (1993). Safe havens: Portraits of educational effectiveness in community art centers that focus on education in economically disadvantaged communities. Cambridge, MA: Harvard Project Zero, Project Co-Arts.

De Genova, N./Ramos-Zayas, A. Y. (2003). Latino rehearsals: Racialization and the politics of citizenship between Mexicans and Puerto Ricans in Chicago. Journal of Latin American Anthropology, 8 (2), 18-57.

Diversi, M./Mecham, C. (2005). Latino(a) students and Caucasian mentors in a rural after-school program: Towards empowering adult-youth relationships. Journal of community psychology, 33 (1), 31-40.

Durlak, J. A./Mahoney, J. L./Bohnert, A. M./Parente, M. E. (2010). Developing and improving after-school programs to enhance youth's personal growth and adjustment: A special issue of AJCP. American Journal of Community Psychology, 45 (3-4), 285-293.

Eccles, J. S./Gootman, J. A. (2002). Community programs to promote youth development. Washington, DC: National Academy Press.

Erikson, E. H. (1968). Identity youth and crisis. New York: W. W. Norton \& Company, Inc.

Flyvbjerg, B. (2006). Five misunderstandings about case-study research. Qualitative Inquiry, 12 (2), 219-245.

Fredricks, J. A./Alfred-Liro, C. J./Hruda, L. Z./Eccles, J. S./Patrick, H./Ryan, A. M. (2002). A qualitative exploration of adolescents' commitment to athletics and the arts. Journal of Adolescent Research, 17 (1), 68-97.

García-Coll, C./Magnuson, K. (1997). The psychological experience of migration: A developmental perspective. In: A. Booth/A. C. Crouter/N. Landale (Eds.), Immigration and the family: Research and policy on the U.S. immigrants (pp. 91131). Mahwah, New Jersey: Lawrence Erlbaum Associates.

Gaviria, A./Mejía, C. (2005). Las varias caras de la diáspora: Los nexos de los emigrantes con su país de origen. Centro de Estudios sobre Desarrollo Económico, CEDE (29), 1-52.

Gentemann, K. M./Whitehead, T. L. (1983). The cultural broker concept in bicultural education. Journal of Negro Education, 52 (2), 118-129.

Guarnizo, L. E./Díaz, L. M. (1999). Transnational migration: A view from Colombia. Ethnic and Racial Studies, 22 (2), 397-421.

Guarnizo, L. E./Espitia, M. (2007). Colombia. In: M. C. Waters/R. Ueda/H. B. Marrow (Eds.), The new Americans: A guide to immigration since 1965 (pp. 371385). Cambridge, MA: Harvard University Press.

Guarnizo, L. E./Sánchez, A. I. (1998). Emigración colombiana a los Estados Unidos: Trans-territorialización de la participación política y socioeconómica. In: L. A. Restrepo (Ed.), Estados Unidos: Potencia y prepotencia (pp. 293-334). Santafé de Bogotá: Tercer Mundo Editores. 
Guarnizo, L. E./Sánchez, A. I./Roach, E., M. (1999). Mistrust, fragmented solidarity, and transnational migration: Colombians in New York and Los Angeles. Ethnic and Racial Studies, 22 (2), 367-396.

Guarnizo, L. E./Smith, M. P. (1998). The locations of transnationalism. In: M. P. Smith/L. E. Guarnizo (Eds.), Transnationalism from below. (pp. 3-31). New Brumswick, NJ: Transaction Publishers.

Halpern, R. (1999). After-school programs for low-income children: Promise and challenges. The Future of Children When School is Out, 9 (2), 81-95.

Harris, E. (2007). Out-of-school time opportunities for immigrant youth [Electronic Version]. The Evaluation Exchange, 12. Available Online at: http://www.hfrp. org/var/hfrp/storage/original/application/c2dda25c82b71415c1ea669ffbf55925. pdf, [22.08.2014].

Harter, S. (1990). Self and identity development. In: S. S. Feldman/G. R. Elliott (Eds.), At the threshold: The developing adolescent (pp. 352-387). Cambridge, MA: Harvard University Press.

Harvey, A. R./Hill, R. B. (2004). Africentric youth and family rites of passage program: promoting resilience among at-risk African American youths. Social Work, 49 (1), 65-74.

LeCompte, M. D./Preissle, J./Tesch, R. (1993). Ethnography and qualitative design in educational research (Second ed.). San Diego: Academic Press.

Lerner, R. M./Dowling, E. M./Anderson, P. M. (2003). Positive youth development: Thriving as the basis of personhood and civil society. Applied Developmental Science, 7 (3), 172-180.

Lewins, A./Silver, C. (2007). Using software in qualitative research: A step by step guide. Los Angeles, CA: SAGE.

Little, P. M. D./Wimer, C./Weiss, C. H. (2008). After school programs in the 21st century: Their potential and what it takes to achieve it. Issues and opportunities in out-of-school time evaluation (10), 1-12.

Louie, V. S. (2006). Second-generation pessimism and optimism: How Chinese and Dominicans understand education and mobility through ethnic and transnational orientations. International Migration Review, 40 (3), 537-572.

MacDonald, V.-M./Carrillo, J. F. (2010). The United Status of Latinos. In: Murillo/ Enrique G./S. Villenas/R. T. Galvan/J. Sanchez Muñoz/C. Martinez/M. (Eds.), Handbook of Latinos and Education (pp. 8-26). New York: RoutledgeFalmer.

Maddux, J. E. (2002). Self-efficacy. In: C. R. Snyder/J. J. Lopez (Eds.), The Handbook of Positive Psychology (pp. 277-287). Oxford; New York: Oxford University Press.

Mahoney, J. L./Larson, R./Eccles, J. S./Lord, H. (2005). Organized activities as developmental contexts for children and adolescents. In: J. L. Mahoney/R. Larson/J. S. Eccles (Eds.), Organized activities as context of development: Extracurricular activities, after-school and community programs (pp. 3-22). Mahwah, NJ: Lawrence Erlbaum Associates.

Mason, M. J./Chuang, S. (2001). Culturally-based after-school arts programming for low-income urban children: Adaptive and preventive effects. Journal of Primary Prevention, 22 (1), 45-54.

Masten, A. S./Coastworth, J. D. (1998). The development of competencies in favorable and unfavorable environments: Lessons from research on successful children. American Psychologist, 53 (2), 205-220. 
Masten, A. S./Reed, M.-G. J. (2002). Resilience in development. In: C. R. Snyder \& J. J. Lopez (Eds.), The Handbook of Positive Psychology (pp. 74-88). Oxford; New York: Oxford University Press.

Maxwell, J. A. (1996). Qualitative research design: An interactive approach (Vol. 41). Thousand Oaks: Sage.

Maxwell, J. A. (2005). Qualitative research design: An interactive approach (2nd ed. Vol. 41). Thousand Oaks: Sage.

Miles, M. B./Huberman, A. M. (1994). Qualitative data analysis: An expanded sourcebook: (Second ed.). Thousand Oaks: Sage Publications.

Morrow, S. L. (2005). Quality and trustworthiness in qualitative research in counseling psychology. Journal of Counseling Psychology, 52 (2), 250-260.

Nakkula, M. J./Ravitch, S. M. (1998). Matters of interpretation: Reciprocal transformation in therapeutic and developmental relationships with youth. San Francisco: Jossey-Bass.

Noam, G. G./Biancarosa, G./Dechausay, N. (2003). Afterschool education: Approaches to an emerging field. Cambridge, MA: Harvard Education Press.

O'Cadiz, P. (2003). Affirming culture and building citizenship through after-school curricula. In: G. G. Noam/G. Biancarosa/N. Dechausay (Eds.), Afterschool education: Approaches to an emerging field (pp. 121-126). Cambridge, MA: Harvard Education Press.

Offer, D./Schonert-Reichl, K. A. (1992). Debunking the myths of adolescence: Findings from recent research. Journal of the American Academy of Child \& Adolescent Psychiatry, 31 (6), 1003-1014.

Ogbu, J. U./Simmons, H. (1998). Voluntary and involuntary minorities: A culturalecological theory of school performance with some implications for education. Anthropology and Education Quarterly, 29, 155-188.

Ojeda, L./Flores, L./Meza, R./Morales, A (2011). Culturally competent qualitative research with Latino immigrants. Hispanic Journal of Behavioral Sciences, 33 (2), 184-203.

Phinney, J. S. (1990). Ethnic Identity in adolescents and adults: Review of research. Psychological Bulletin, 108 (3), 499-514.

Phinney, J. S. (1992). The Multigroup Ethnic Identity Measure: A new scale for use with diverse groups. Journal of Adolescent Research, 7, 156-176.

Phinney, J. S./Horenczyk, G./Liebkind, K./Vedder, P. (2001). Ethnic identity, immigration, and well-being: An interactional perspective. Journal of Social Issues, 57 (3), 493-510.

Pineda, C. G. (2014). Let the right one in: Ethnic boundaries in a Colombian immigrant youth organization. Department of Child and Adolescent Studies, California State University at Fullerton, California. Manuscript in preparation.

Pittman, K. J./Irby, M. A./Yohalem, N./Wilson-Ahlstrom, A. (2004). Blurring the lines for learning: The role of out of school programs as complements to formal learning. New Directions for Youth Development, Spring 2004 (101), 75-113.

Rhodes, J. E. (2004). The critical ingredient: Caring youth-staff relationships in after-school settings. New Directions for Youth Development, Spring 2004 (101), $145-161$.

Riggs, N. R. (2006). After-school program attendance and the social development of rural latino children of immigrant families. Journal of Community Psychology, 34 (1), 75-87. 
Riggs, N. R./Bohnert, A. M./Guzman, M. D./Davidson, D. (2010). Examining the potential of community-based after-school programs for Latino youth. American Journal of Community Psychology, 45 (3-4), 417-429.

Roffman, J. G./Suárez-Orozco, C./Rhodes, J. E. (2003). Facilitating positive development in immigrant youth: The role of mentors and community organizers. In: F. A. Villarruel/D. F. Perkins/L. M. Borden/J. G. Keith (Eds.), Community youth development: Programs, policies and practices (pp. 80-90). Thousand Oaks, CA: Sage Publications.

Rumbaut, R. G. (2009). Pigments of our imagination: On the racialization and racial identities of "Hispanics" and "Latinos". In: J. A. Cobas/J. Duany/J. R. Feagin (Eds.), How the United States racializes Latinos: White hegemony and its consequences (pp. 15-36). Boulder: Paradigm.

Schinke, S. P./Botvin, G. J./Trimble, J. E./Orlandi, M. A./Gilchrist, L. D./Locklear, V. S. (1988). Preventing substance abuse among American-Indian adolescents: A bicultural competence skills approach. Journal of Counseling Psychology, 35 (1), 87-90.

Scott, J./Aldwin, D. (1998). Restrospective versus prospective measurement of life histories in longitudinal research. In: J. Z. Giele/G. H. Elder (Eds.), Methods of life course research: qualitative and quantitative approaches (pp. 98-127). Thousand Oaks, CA.: Sage Publications.

Shinew, K. J./Hibbler, D. K./Anderson, D. M. (2000). The academic cultural enrichment mentorship program: An innovative approach to serving African American youth. Journal of Park and Recreation Administration, 18, 103-121.

Simpkins, S./O’Donnell, M./Delgado, M./Becnel, J. (2011) Latino adolescents' participation in extracurricular activities: How important are family resources and cultural orientation? Applied Developmental Science, 15 (1), 37-50.

Sommer, D. (2006). Cultural agency in the Americas. Durham: Duke University Press.

Stevens, A./Owen, G. (1998). Black Teens for Advancement (BTA): 1997-98 Evaluation Report. St. Paul, MN: Wilder Research Center.

Strauss, A./Corbin, J. (1990). Basics of qualitative research: Grounded theory, procedures and techniques. Newbury Park: CA: Sage Publications.

Suárez-Orozco, C. (2000). Identities under siege: Immigration stress and social mirroring among the children of immigrants. In: A. Robben/M. Suárez-Orozco (Eds.), Cultures under siege: Social violence and trauma (pp. 194-226). Cambridge: Cambridge University Press.

Suárez-Orozco, C./Suárez-Orozco, M. (2001). Children of immigration. Cambridge: Harvard University Press.

Thomsen, D. K./Brinkmann, S. (2009). An interviewer's guide to autobiographical memory: Ways to elicit concrete experiences to avoid pitfalls in interpreting them. Qualitative Research in Psychology, 6 (4), 294-312.

U.S. Census Bureau. (2003). Hispanic population reaches all-time of 38.8 million: United States Department of Commerce News.

Vandell, D. L./Pierce, K. M./Dadisman, K. (2005). Out-of-school settings as a developmental context for children and youth. In: R. Kail (Ed.), Advances in child development (Vol. 33) (pp. 43-77). Oxford: Elsevier.

Villarruel, F. A./Montero-Sieburth, M./Dunbar, C./Outley, C. W. (2005). Dorothy, there is no yellow brick road: The paradox of community youth development 
approaches for Latino and African American Urban Youth. In: J. L. Mahoney/R. Larson/J. S. Eccles (Eds.), Organized activities as context of development: Extracurricular activities, after-school and community programs (pp. 111-129). Mahwah, NJ: Lawrence Erlbaum Associates.

Viruell-Fuentes, E. A. (2006). "My heart is always there": The transnational practices of first-generation Mexican immigrant and second-generation Mexican American women. Identities: Global Studies in Culture and Power, 13, 335-362.

Waldfogel, J./Lahaie, C. (2007). The role of preschool and after-school policies in improving the school achievement of children of immigrants. In: J. E. Lansford/K. D. Deater-Deckard/M. H. Bornstein (Eds.), Immigrant families in contemporary society (pp. 177-193). New York, NY: The Guildford Press.

Weisner, T. S. (2002). Ecocultural understanding of children's developmental pathways. Human Development, 45, 275-281.

Weiss, H. B./Little, P. M. D./Bouffard, S. M. (2005). More than just being there: Balancing the participation equation. New Directions for Youth Development (105), $15-31$.

Whaley, A. L./McQueen, J. P. (2004). An Afrocentric program as primary prevention for African American youth: Qualitative and quantitative exploratory data. The Journal of Primary Prevention, 25 (2), 253-269.

Yin, R. K. (2014). Case study research: Design and methods (Fifth ed.). Los Angeles, CA: SAGE Publications. 